\title{
Efficient energy consumption for indoor mobile robot prototype under illumination
}

\author{
Seilla Angelina ${ }^{1, *}$, Shofuro Afifah ${ }^{1}$, Paramadina Susamti ${ }^{1}$, Rizki Ardianto Priramadhi ${ }^{1}$, and Denny Darlis ${ }^{2}$ \\ ${ }^{1}$ Telkom University, School of Electrical Engineering, J1. Telekomunikasi, Bandung, Indonesia \\ ${ }^{2}$ Telkom University, Diploma of Telecommunication Engineering, Jl. Telekomunikasi, Bandung, Indonesia
}

\begin{abstract}
In the next 20 years, energy consumption is expected to increase up to $30 \%$ and it will affect energy crisis. Energy crisis can be resolved by energy efficiency. The context of this paper is about the energy efficiency of a mobile robot in the industrial warehouse. Communications media which commonly used in mobile robot navigation such as Laser need large power consumption. In order to reduce power consumption, the system of this paper is designed to use visible light communication (VLC) for mobile robot navigation because VLC only utilize lights as the transmitter. Method of this paper is sending the data contained navigation coordinates which modulated on the lighting system, then data will be received by the photodetector and processed as mobile robot's navigation. From above system, by using 5,68-watt power on lighting system can be used to transmit navigation data with the range up to 2 meters. In the receiver side, a photodetector which uses as receiver generate maximum power 4,14 watt at $10 \mathrm{~cm}$ of height between transmitter and receiver while minimum generated power is 3,21 watt at $250 \mathrm{~cm}$ of height. The conclusion of this paper is generated power by a photodetector in navigation process mobile robot is affected by angle and distance between transmitter and receiver.
\end{abstract}

\section{Introduction}

Mobile robots are widely used in any application. Industrial sector are using mobile robots to store and retrieve items in the warehouse. Mobile robots usually have multiple components such as motors, sensors, microcontroller and embedded computers. DC motors transform direct current into mechanical energy and are often used to drive the mobile robots. Sensors are used to collect data from environment and provide information for robots. Most often used sensors are vision, infrared, sonar, and laser rangers [1]. M. M. Oliveira et al. on the table 1 . show the power consumption for each components in mini mobile robot forklift [2]. Each component in mobile robot system required energy and it causes energy consumption became the most important challenge for mobile robots. Energy consumption of mobile robots can be minimized by improving the energy efficiency of a robot system. Optimization of robot applications can also contribute to energy conservation [3]. There are various research concerning efficient energy consumption for mobile robots. Motion planning has emerged as one of the best ways to minimize energy consumption of mobile robots [4]. In 2010, Morales et al. adopted a kinematic approach to provide a simplified power consumption model and identification for wheeled skid-steer mobile robotic vehicles on hard horizontal ground. The model estimates the motor power consumption as a function of the left- and right-side wheels' speeds [5]. Zhang et al. introduced an approach to minimize the power consumption of a mobile robot by controlling its traveling speed and the frequency of its onboard processor simultaneously [6]. The minimum energy was achieved by reducing the steering actuation of robots optimal trajectory planning in [7]. Existing studies on energy reduction for robots focus on motion planning to reduce motion power. However, other components like sensing, control, communication and computation also consume significant amounts of power. It is important to consider all components to achieve better energy efficiency [1]. Therefore, this study propose system by utilizing illumination of visible light as media communication (VLC) in indoor positioning system of Mobile Robot to reduce energy consumption with main objective to maximizing received power on the receiver side for mobile robot navigation system.

Table 1. Energy consumption of mini robotic forklift.

\begin{tabular}{|l|l|c|c|}
\hline \multicolumn{4}{|c|}{ Components of the Mini-robotic Forklift } \\
\hline Component & \multicolumn{1}{|c|}{ Description } & $\begin{array}{c}\text { Power } \\
(\text { Vdc })\end{array}$ & $\begin{array}{c}\text { Total nominal } \\
\text { current (A) }\end{array}$ \\
\hline 1 laser & $\begin{array}{l}\text { Hoyuko URG- } \\
\text { 04LX }\end{array}$ & 5 & 0.5 \\
\hline 8 Sonar & $\begin{array}{l}\text { LV MaxSonar } \\
\text { EZ-01 }\end{array}$ & $\begin{array}{c}2.5- \\
5.5\end{array}$ & 0.016 \\
\hline $\begin{array}{l}\text { 1 Fork } \\
\text { motor }\end{array}$ & $\begin{array}{l}\text { RE-max 17/4.5 } \\
\text { 216010 }\end{array}$ & 12 & 0.414 \\
$\begin{array}{l}\text { Wheel } \\
\text { motor }\end{array}$ & $\begin{array}{l}\text { RE-max 29 } \\
\text { 226802 }\end{array}$ & 12 & 2.16 \\
\hline 1 Controller & EPOS 24/1 & $9-24$ & 0.15 \\
\hline 2 Controller & EPOS 24/5 & $11-24$ & 0.3 \\
\hline
\end{tabular}

\footnotetext{
* Corresponding author: angelina.seilla61@gmail.com
} 


\section{Method}

Basically, every warehouse must have a lighting system as shown in Fig. 1 Mobile robot system in this paper will be designed to utilize illuminance of visible light which coming from warehouse's lighting system for navigation of mobile robot purpose.

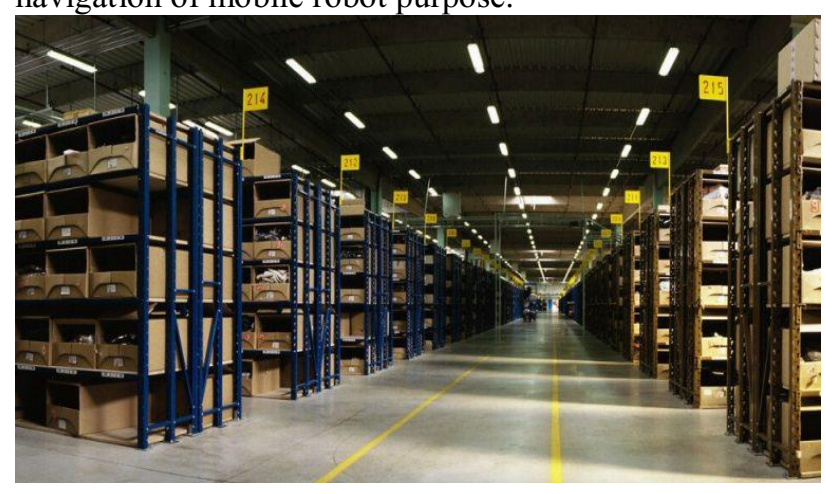

Fig. 1. Warehouse environment (source: www.sanliledlighting.com).

\subsection{System modelling}
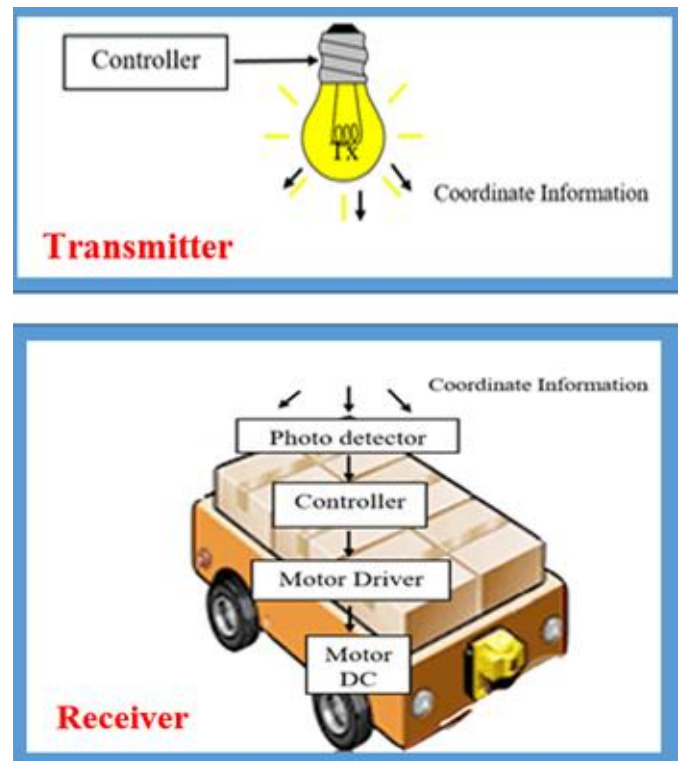

Fig. 2. Block diagram of system.

Navigation system of this paper designed that consists of transmitter and receiver. LED at the warehouse's lighting system will be used as an antenna transmitter. An LED was a suitable component because of its relatively linear relation between current and light intensity [8]. General idea of this system is to modulate light intensity of LED to be able to transmit data[9]. Initially, data contained coordinate information on the controller will be inserted into LED driver. Furthermore, LED driver will propagate a modulated signal to free space by using visible light medium. Intensity of the visible light will be received by photodiode and converted into electrical signal. Then, a signal which has been received by receiver will be processed by controller to drive mobile robot in the navigation process.

\subsection{Photodetector design}

This system using photodiode as photodetector on the receiver side because photodiode have a fast response time, a spectral sensitivity in the visible spectrum and a large radiant sensitive area [8]. Receiver in this system is equipped with signal conditioner such as Transimpedance-Amplifier and Pre-Amplifier as shown in Fig. 3.

Photodiode will receive light intensity from LED and then will be converted into electrical signal. Transimpedance Amplifier (TIA) will convert electrical signal from photodiode output into electrical voltage. Pre-Amplifier is used to amplify output signal from Transimpedance Amplifier in order to reduce interference which coming from another visible light.

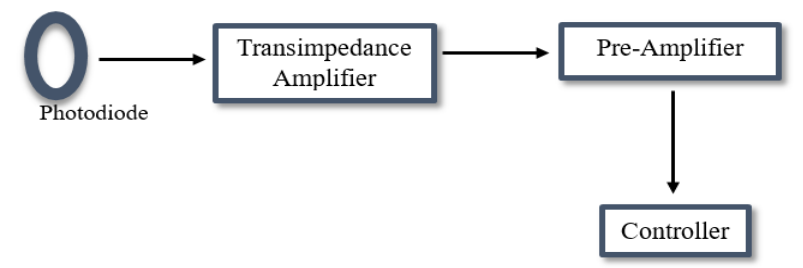

Fig. 3. Block diagram of receiver.

\subsection{Experimental scenario}

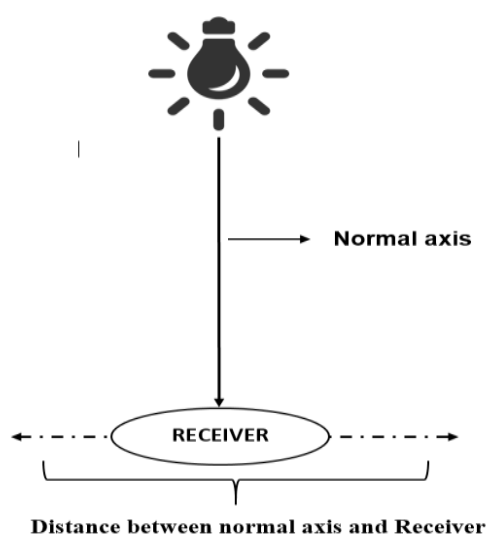

Fig. 4. Experimental scenario at different distance between normal axis and receiver.

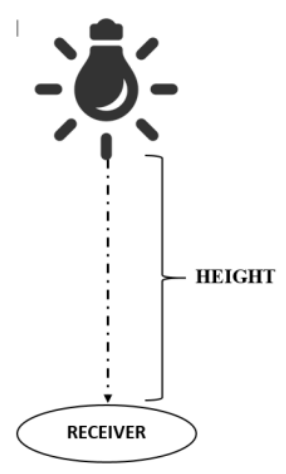

Fig. 5. Experimental scenario at different height between transmitter and receiver. 
Experiment of this system divided into two parts. The first as shown in Fig. 4, this experiment is performed by changing distance between normal axis and receiver. The second experiment is performed by changing height between transmitter and receiver, as shown in Fig. 5. Both of this experiment were conducted to see relation between power which will be received by photodiode againts distance between normal axis and receiver and also height between transmitter and receiver.

\section{Result and discussion}

Based on experiments that have been done, The results are described in this section.

\subsection{Efficient power consumption}

The system in this paper is more efficient power consumption than mobile robot that use laser beacons in navigation system. It can been seen in table 3 , system which using illuminance in navigation system will generated power from photodetector that used as receiver in navigation process. While in table 2 it can be seen that mobile robots using laser beacons in navigation system need power to be operated with amount 5 volt of supply and 0,5 ampere of nominal current. It also have no generated power from the navigation process [10].

Table 2. Generated energy from navigation purpose.

\begin{tabular}{|c|c|c|}
\hline Component & $\begin{array}{c}\text { Received voltage } \\
\text { (v) }\end{array}$ & $\begin{array}{c}\text { Received current } \\
\text { (a) }\end{array}$ \\
\hline Photodetector & $0,51-0,599$ & $6,04-6,92$ \\
\hline
\end{tabular}

\subsection{Effect of distance between normal axis and receiver changes againts generated power}

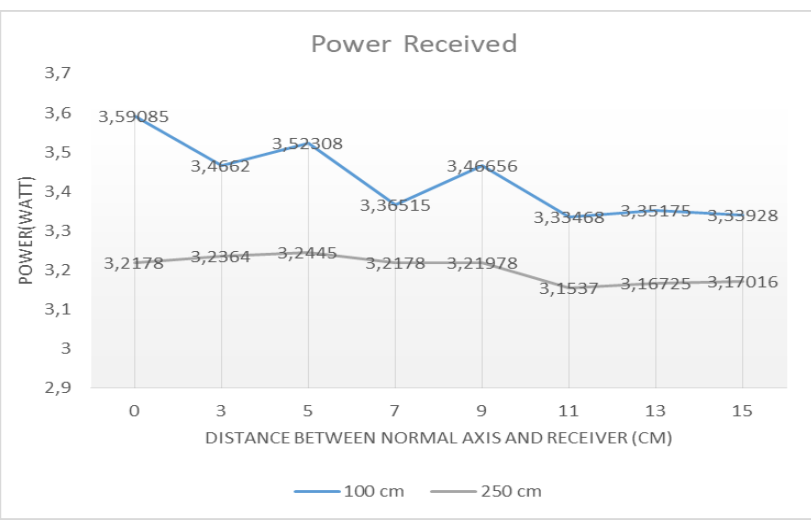

Fig. 6. Power received in different distance between normal axis to receiver.

In Fig. 6 it can be seen that at $100 \mathrm{~cm}$ of height, maximum power which have been generated by photodiode in the navigation process is 3,59 watt which is at zero $\mathrm{cm}$ of the distance between normal axis and receiver. While minimum power which have been generated is at $15 \mathrm{~cm}$ of the distance between normal axis and receiver which is equal to 3,33 watt. When distance between normal axis to receiver is being enlarged, power that will be generated by photodiode in navigation process will be smaller. From this results experiment obtained relation between power received and distance between normal axis to receiver is linier.

\subsection{Effect of height between transmitter and receiver changes againts generated power}

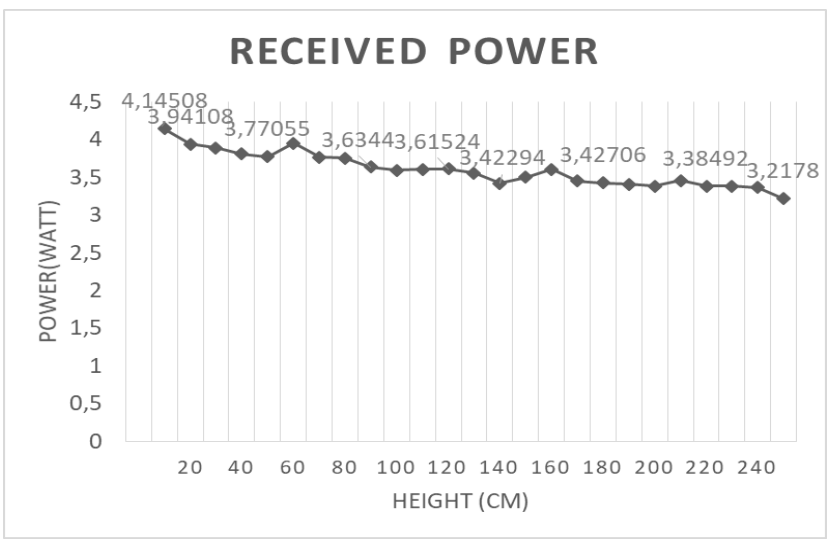

Fig. 7. Power received in different height.

In Fig. 7 Shows difference amount of power received by photodiode in the navigation process towards height between transmitter and receiver. The experiment results obtained, maximum power that have been generated by photodiode is equal 4,14 watt which located at $10 \mathrm{~cm}$ of height between transmitter to receiver. While minimum power that have been generated is at $250 \mathrm{~cm}$ of height between transmitter to receiver which is equal to 3,21 watt. From this results experiment also obtained relation between power received and height between transmitter to receiver is linier.

\section{Conclusions}

Based on experiment results that have been obtained, mobile robot which using illuminance in the navigation system is more efficient in energy consumption compared with mobile robot that used laser-beacon in the navigation system. From experiment results also known that height between transmitter to receiver and distance between normal axis to receiver will affect power that will be generated by photodiode in navigation process.

\section{Future work}

It could be interesting if the system equipped with energy storing mechanism. Energy that have been generated by photodiode will be saved in storage system and then it will be used for another warehouse devices.

We gratefully thanks to electrical engineering faculty of telkom university that have been support this research. We also thanks to mentor that have been provide advice and guidance in the work of this research. 


\section{References}

1. Y.Mei, Y.H. Lu, Y.C. Hu, and C.S.G. Lee," A Case Study of Mobile Robot's Energy Consumption and Conservation Technique," School of Electrical and Computer Engineering, Purdue University (2005)

2. M. M. Oliveira, J. P. M. Galdames, K. T. Vivaldini, D. V. Magalhães, and M. Becker, Battery State Estimation for Applications in Intelligent Warehouses, Presented at IEEE International Conference on Robotics and Automation Shanghai International Conference Center, Shanghai, China, May 9-13 (2011)

3. S.E. Mushi, Z.Lin, and P.E. Allaire, Design, construction, and modeling of a flexible rotor active magnetic bearing test rig, IEEE/ASME Trans. Mechatronics vol.17, no.6, pp.1170-1182, Dec (2012)

4. R. Datouo, F.B. Motto, B.E. Zobo, A.Melingui, I. Bensekrane, and R. Merzouky, Optimal motion planning for minimizing energy consumption of wheeled mobile robots, Presented at International Robotics and Biometics, Macao, China, Dec (2017)

5. J. Morales, J.L. Martinez, A. Mandow, A.P. Boter and A.G. Cerezo, Simplified power consumption modeling and identification for wheeled skid-steer robotic vehicles on hard horizontal ground, in IEEE/RJ International Conference on Intelligent Robots and System, Taiwan (2010)

6. W. Zhang, Y. Lu, and J. Hu, Optimal solutions to a class of power management problems in mobile robot, Automatica (J. of IFAC), vol. 45, no. 4, pp. 989-996, April (2009)

7. J. Yang, Z. Qu, J. Wang, and K. Conrad, Comparison of optimal solutions to real time path planning for a mobile vehicle, IEEE Trans. Syst., Man, Cybern.A, Syst. Humans, vol. 40, no.4, pp.721-731, July (2010)

8. E. F. Schubert, Light-Emitting Diodes (2nd Edition). book section 23, p. 391 (Cambridge University Press, 2006)

9. B. Adam, E. Viktor, H. Daniel, H. Philip, N. Jakob, and S. Albin, An implementation of a visible light communication system based on LEDs, thesis, (Chalmer University of Technology, Gothenburg, Sweden, 2015)

10. Hyunhak, S.Hajun, P.Moonho, K.Jaeyong, W. Seungbeom, and K. Sungshin, Independence Localization System for Mecanum Wheel AGV, Presented at The 22nd IEEE International Symposium on Robot and Human Interactive Communication Gyeongju, Korea, August 26-29 (2013) 